\title{
Endometriosis: Survey of Current Diagnostic and Therapeutic Options and Latest Research Work
}

\section{Endometriose: Überblick über aktuelle Diagnostik- und Therapieoptionen und neueste Forschungsansätze}

Authors

Affiliations
I. Juhasz-Böss ${ }^{1}$, M. W. Laschke² ${ }^{2}$, . Müller ${ }^{3}$, P. Rosenbaum ${ }^{1}$, S. Baum ${ }^{1}$, E. F. Solomayer ${ }^{1}$, U. Ulrich ${ }^{3}$

${ }^{1}$ Klinik für Frauenheilkunde, Geburtshilfe und Reproduktionsmedizin, Universitätsklinikum des Saarlandes, Homburg/Saar

${ }^{2}$ Institut für Klinisch-Experimentelle Chirurgie, Universität des Saarlandes, Homburg

${ }^{3}$ Klinik für Gynäkologie und Geburtshilfe, Martin-Luther-Krankenhaus, Berlin
Key words

- endometriosis

- infertility

dyspareunia

Schlüsselwörter

- Endometriose

- Infertilität

- Dyspareunie

Deutschsprachige Zusatzinformationen online abrufbar unter: www.thieme-connect.de/ ejournals/toc/gebfra

\begin{abstract}
received 24.5.2013
revised 29.6.2014

accepted 30.6.2014
\end{abstract}

Bibliography

DOI http://dx.doi.org/

$10.1055 / \mathrm{s}-0034-1382884$

Geburtsh Frauenheilk 2014; 74

733-742 @ Georg Thieme

Verlag KG Stuttgart · New York . ISSN 0016-5751

\section{Correspondence}

\section{PD Dr. Ingolf Juhasz-Böss}

Uniklinikum Saarland

Frauenklinik

Kirrbergerstraße 100

66424 Homburg/Saar

Ingolf.Juhasz-Boess@

uniklinikum-saarland.de

\section{Abstract \\ $\nabla$}

Endometriosis is one of the most frequent benign diseases in women of child-bearing age. The main symptoms are chronic upper abdominal pain and infertility. However, the aetiology and pathogenesis of endometriosis are as yet insufficiently clarified. Thus, therapy is mainly symptomatic with laparoscopic surgery being the gold standard. The aim of drug therapy is to achieve a hypo-oestrogenic condition. In cases of severe endometriosis and a desire to have children there is often an indication for assisted reproduction. The present article illustrates almost all current aspects on the diagnosis of and therapy of endometriosis. From the clinical viewpoint, emphasis is placed on the rare cases of deeply infiltrating endometriosis that are, however, accompanied with a high morbidity. Current therapeutic options in cases of infertility are also presented in more detail. Furthermore, special attention is paid to the latest research results from both clinical and basic research fields in order to demonstrate our current knowledge on the pathogenesis and, where possible, potentially related therapeutic options.

\section{Introduction, Definitions and Epidemiology \\ $\nabla$}

Endometriosis is one of the most frequent benign diseases of the fertile woman and is defined as the presence of endometrium outside of the uterine cavity. The prevalence rates given in the literature vary widely. It is estimated that in Germany about 40000 new cases occur each year [1]. Risk factors for endometriosis are, among others, the duration of period bleeding, length of the menstrual cycle, number of pregnancies, number of miscarriages and smoking status [2]. The pathogenesis of the

\section{Zusammenfassung \\ $\nabla$}

Die Endometriose ist eine der häufigsten gutartigen Erkrankungen der Frau im reproduktionsfähigen Alter. Hauptsymptome sind chronische Unterbauchschmerzen und Infertilität. Ätiologie und Pathogenese der Endometriose sind jedoch bisher unzulänglich geklärt. Es erfolgt daher eine vornehmlich symptomatische Therapie, wobei die laparoskopische Entfernung als operativer „Goldstandard“ gilt. Ziel der medikamentösen Therapie ist das Erreichen eines hypoöstrogenen Zustands. Bei schwerer Endometriose und Kinderwunsch ergibt sich häufig die Indikation für eine assistierte Reproduktion. Die vorliegende $\mathrm{Ar}$ beit fasst alle aktuellen Aspekte zur Diagnostik und Therapie der Endometriose zusammen. Dabei wird klinisch ein Schwerpunkt auch auf die zwar seltenere, jedoch mit hoher Morbidität verbundene tief infiltrierende Endometriose gesetzt. Auch zeitgemäße Therapieoptionen bei Infertilität werden näher dargestellt. Zudem wird ein Schwerpunkt auf neueste Forschungsansätze gelegt, um sowohl Klinikern als auch Wissenschaftlern aktuelle Erkenntnisse zur Pathogenese und ggf. daraus resultierenden Therapieoptionen darzustellen.

disease is even today not completely clarified. Although endometriosis is a benign disease, it can spread to other organs through infiltrative growth and thus require extensive surgery. The main symptoms of the disease are sterility and chronic pain $[3,4]$.

Current therapeutic concepts are mainly aimed at suppression of ovarian function and analgesia in addition to the operative management. For this purpose above all gestagen-rich contraceptives, pure gestagen und GnRH analogues are employed. For pain therapy NSAR are used preferentially. In spite of the use of known therapeutic 
strategies in some cases insufficient relief of the endometriosisrelated complaints or disease recurrence can occur.

The disease is thus also of economic relevance. Beside the medical expenses, above all the patients' inability to work is appreciable $[1,5]$. Repeated surgery, the in part chronic course as well as the delayed diagnostic confirmation after year-long symptoms and complaints results in a high medical expenditure [6].

The present article aims to give an actual survey of the diagnostic and therapeutic procedures as well as to present the latest research results on the subject of endometriosis.

\section{Aetiology of Endometriosis: Classic Theories and Latest Research Approaches \\ $\nabla$}

Although endometriosis is one of the most investigated gynaecological clinical entities, many aspects of the aetiology and pathogenesis of the disease have still not been completely clarified and thus represent a focus of current research on endometriosis.

The classical theories on the development of endometriosis include the "coelom metaplasia theory" (according to Meyer) and the "theory of embryonic cell remains" according to which the endometriosis lesions develop from tissue of embryonic origin, as well as the "theory of lymphovascular metastasis", which proposes that endometrial cells, similar to tumour cells, spread via lymphatic pathways or blood vessels and that in this way endometriosis lesions can develop in various positions in the body [7]. Today the most widely accepted theory on the development of endometriosis is, however, the "implantation theory" according to Sampson [8]. This is based on the assumption that during menstruation, vital endometrium reaches the abdominal cavity from the uterus in a retrograde manner via the tubes. Favourable conditions there lead to implantation of tissue fragments on the peritoneum and thus to the development of endometriosis. However, retrograde menstruations are certainly physiological and can be detected in up to $90 \%$ of all women who undergo laparoscopy [9]. Thus there is no doubt that the development of endometriosis depends on many other pathogenic mechanisms, thus rendering it a typical multifactorial clinical entity.

Numerous studies have in the meantime indicated that there is a genetic predisposition for endometriosis [10]. For this reason genome-wide association studies are underway in order to identify the corresponding genetic factors. Although in the course of these studies 3 potential gene loci have already been found that are with the highest probability associated with the occurrence of endometriosis in Japanese and European women, it is still necessary to confirm such results in a larger number of cases and to correlate the obtained data with the various clinical subtypes of endometriosis [11]. In addition epigenetic studies are needed to clarify how certain environmental factors influence the disease. In this context, dioxins must be considered as potential diseasetriggering environmental toxins [12]. Furthermore, certain components of foodstuffs such as, e.g., fatty acids and their derivatives, are being discussed as factors influencing the disease [13]. Various immunological aspects also play an important role in the pathogenesis of endometriosis, whereby the disease shows marked similarities with typical autoimmune diseases [14]. Thus, it was shown that in the course of endometriosis autoantibodies against endometrial antigens such as, e.g., transferrin or alpha 2HS glycoprotein, are formed, and which can often in part be responsible for the infertility frequently observed in endometriosis patients $[15,16]$. Also concentration fluctuations of cytotoxic and activated lymphocytes peripheral blood during the menstrual cycle appear to play a certain role. The fluctuations of regulatory $\mathrm{T}$ cells detected during endometriosis can be attributed to a changed immune response [17]. Furthermore, endometriosis is characterised by a chronic inflammatory reaction with elevated concentrations of inflammatory cytokines in serum and the peritoneal fluid [18]. Elevated numbers of macrophages, dendritic cells and natural killer cells are seen in the peritoneum which, for as yet insufficiently investigated reasons, are however not able to recognise and degrade the endometrium tissue scattered in the abdominal cavity [19]. This chronic inflammatory reaction, in turn, leads to an increased production and an inhibited degradation of reactive oxygen species [20]. Accordingly, the administration of substances with an antioxidative action could represent a meaningful supplement to the current therapeutic options.

The basal parts of the endometrium contain endometrial stem cells and progenitor cells [21], which explains the high regeneration potential of this tissue. This is at present under discussion as a further cause for the occurrence of endometrium lesions. Thus, it is assumed that stem cells reach the abdominal cavity via retrograde menstruation and under suitable conditions can then differentiate into endometriosis lesions [22]. This assumption is supported by the observation that the glandular cells of some endometriosis lesions are of monoclonal origin [22]. In addition, it is possible that also extrauterine, circulating stem and progenitor cells from bone marrow contribute appreciably to the formation of endometriosis lesions. Thus, it has been shown in a mouse model that not only glandular but also stromal cells from bone marrow cells can develop into endometriosis lesions [23]. Furthermore, up to $37 \%$ of all endothelial cells in endometriosis lesions are derived from circulating endothelial progenitor cells [24].

A major prerequisite for the long-term survival of endometriosis lesions is angiogenesis, i.e., the generation of new blood vessels [25]. Only in this way can the scattered endometrium tissue, which is initially ischaemic outside the uterus, be adequately supplied with oxygen and nutrients. For this reason, especially the early stages of endometriosis lesions exhibit a reddish colouration caused by a high density of blood vessels and vessel dilatations $[26,27]$. Furthermore, in the past few years numerous angiogenic growth factors have been identified - above all "vascular endothelial growth factor" (VEGF) - which is produced and released in increased amounts in endometriosis, and regulates the ingrowth of new blood vessels in endometriosis lesions [28]. Interestingly, endometrium in the uterus of endometriosis patients already exhibits an elevated angiogenic activity which can favour the process of creation of new endometriosis lesions [29]. Endometriosis thus belongs to the group of angiogenic diseases along with rheumatoid arthritis, psoriasis, diabetic retinopathy as well as tumour growth and metastasis [29]. Accordingly in recent years increasing attention has been paid to analysing the control mechanisms that govern the formation of new blood vessels in endometriosis lesions, in order to identify new targets for a targeted, anti-angiogenic endometriosis therapy [30,31]. In addition, experimental in-vitro and in-vivo studies have already detected numerous members of various substance classes that exert an anti-angiogenic effect on endometriosis lesions. These include growth factor inhibitors, endogenous angiogenesis inhibitors, fumagillin analogues, statins, cyclooxygenase 2 inhibitors, phytotherapeutic agents, immune modulators as well as dopamine agonists [32]. Further clinical trials are needed to clarify to what extent these active principles can be used for an anti-angiogenic 
endometriosis therapy without causing severe side effects in the afflicted patients.

Another area of current research focusses on the mechanisms that contribute to the pain symptomatic of endometriosis. Major contributing factors are considered to be long-term cyclic bleeding of the oestrogen-dependent endometriosis lesions with consecutive inflammatory reactions as well as irritation and invasion of pelvic nerves [33]. Recent investigations, however, have shown that pain transmitting nerve fibres can grow together into endometriosis lesions [34], this is also designated as "neuroangiogenesis" [35]. These nerve fibres in turn increase the pain sensation in the central nervous system [35]. If it were possible - as has already been demonstrated in animal experiments [36] - to inhibit this process by targeted drug measures, we should be able in the future to develop appreciably more effective pain therapies having considerably fewer side effects than the conventional hormone treatment options.

Summarising the current research results, we see that endometriosis is a complex, multifactorial disease for which the aetiology and pathogenesis have not yet been completely clarified. The research findings of the past 10 years, however, do show that molecular and cellular pathomechanisms which contribute to the development of the disease are increasingly being identified. This should provide the possibility in future to develop better targeted, new preventive and therapeutic treatment strategies.

\section{Diagnostic, Clinical Picture and Therapy for Endometriosis}

As recommended in the current guidelines and for the sake of better clarity, the differing manifestations of endometriosis are discussed separately although they often occur in combination [1]. First of all, the following aspects are valid for all manifestations:

Laparoscopy: Laparoscopy (LSC) is a central component in the diagnosis of and therapy for endometriosis. Indication for LSC is: pain, organ changes and/or sterility. Surgical removal of the endometriosis lesions is considered to be the gold standard, on the one hand to control the symptoms and on the other hand for histological work-up [37]. It should be noted that asymptomatic endometriosis in a patient not desiring to have children does not require any surgical or drug treatment [1]. Examination of the case history and the additional use of psychological questionnaires provide valuable information prior to the diagnostic/curative operation and can provide indications for the presence of an endometrial disease and thus support an optimal counselling for the symptomatic patient in the phase of decision-making for surgical clarification [4].

Localisation: Endometriosis preferentially attacks the lesser pelvis and here above all (in order of decreasing frequency) the pelvic peritoneum, the ovaries, the sacrouterine ligament, the rectovaginal septum as well as extragenital manifestations such as, e.g., the rectosigmoid or urinary bladder. Extraperitoneal manifestations are seldom [1].

Staging: In clinical routine endometriosis is subdivided according to its localisation into endometriosis genitalis externa and interna as well as extragenitalis [1]. Unfortunately endometriosis is not uniformly classified, furthermore the current staging is not satisfactory. The most widely used and most frequently used in reproduction medicine is the rASRM classification of the American Society for Reproductive Medicine (ASRM) [38] ( Table 1).
Table 1 rASRM classification of endometriosis (modified from [38]). stage I (minimal): 1-5; stage II (mild): 6-15; stage III (moderate): 16-40; stage IV (pronounced): $>40$.

\begin{tabular}{|c|c|c|c|c|}
\hline & Endometriosis & $<1 \mathrm{~cm}$ & $1-3 \mathrm{~cm}$ & $>3 \mathrm{~cm}$ \\
\hline \multirow[t]{2}{*}{ Peritoneum } & superficial & 1 & 2 & 4 \\
\hline & deep & 2 & 4 & 6 \\
\hline \multirow[t]{7}{*}{ Ovaries } & R superficial & 1 & 2 & 4 \\
\hline & $R$ deep & 4 & 16 & 20 \\
\hline & L superficial & 1 & 2 & 4 \\
\hline & L deep & 4 & 16 & 20 \\
\hline & $\begin{array}{l}\text { Douglas } \\
\text { obliteration }\end{array}$ & partial & complete & \\
\hline & & 4 & 40 & \\
\hline & Adhesions & $<1 / 3$ & $1 / 3-2 / 3$ & $>2 / 3$ \\
\hline \multirow[t]{4}{*}{ Ovaries } & $\mathrm{R}$ thin & 1 & 2 & 4 \\
\hline & $R$ dense & 4 & 8 & 16 \\
\hline & L thin & 1 & 2 & 4 \\
\hline & L dense & 4 & 8 & 16 \\
\hline \multirow[t]{4}{*}{ Tubes } & $\mathrm{R}$ thin & 1 & 2 & 4 \\
\hline & $R$ dense & $4^{*}$ & $8^{*}$ & 16 \\
\hline & Lthin & 1 & 2 & 4 \\
\hline & L dense & $4^{*}$ & $8^{*}$ & 16 \\
\hline
\end{tabular}

* in cases of complete attack or, respectively, complete occlusion of the fimbria ends: 16

Retroperitoneal and deep infiltriating endometriosis are best described by means of the ENZIAN classification $[39,40]$ ( $\bullet$ Fig. 1). However, the stage does not correlate with the degree of complaints, some afflicted women are even asymptomatic.

Tumour marker CA-125: CA-125 is generally elevated in endometriosis patients. However, this tumour marker has no differential diagnostic relevance. In clinical routine its determination is not recommended either for diagnosis or for course control [1].

\section{Peritoneal endometriosis}

Morphology and symptoms

In cases of peritoneal endometriosis a distinction is made between pigmented (=typical) and not pigmented (= atypical) lesions as well as between red, white and black lesions $[26,41]$ ( Fig. 2). These lesions differ above all with regard to their activity, fibrosis, age, etc. It is not clear to what extent the different forms correlate with specific symptoms of endometriosis [42]. Patients with preoperatively pronounced complaints have a higher risk of recurrence than patients with lower pain sensations [43].

\section{Diagnostics}

Peritoneal endometriosis cannot be detected by sonography. Standard procedure in the field of diagnosis of peritoneal endometriosis is laparoscopy [1]. Histological confirmation should also be attempted for peritoneal endometriosis as mentioned above [1].

\section{Surgical and drug therapies}

The main objective is the laparoscopic removal of all peritoneal lesions by means of coagulation, vaporisation or excision [1]. It has not yet been clarified as yet which procedure is the most suitable. In answer to this question there is only one randomised controlled trial and the Cochrane analysis published in 2014 [44, 45].

The aim of drug therapy is to achieve a hypo-oestrogenic status. Endometriosis implants can be regressively changed by means of 


\section{ENZIAN 2012}

Classification of deep infiltrating endometriosis (according to the Endometriosis Research Foundation, SEF)
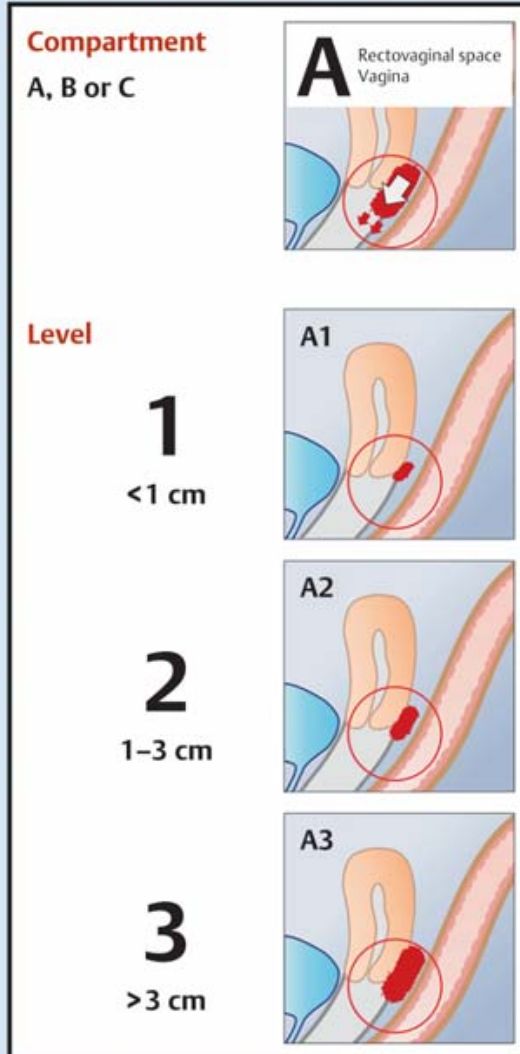
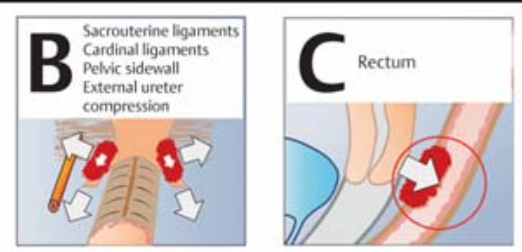

B1
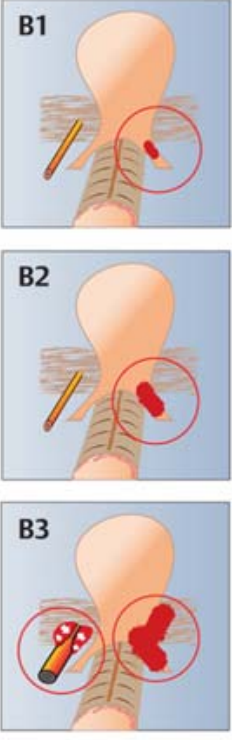
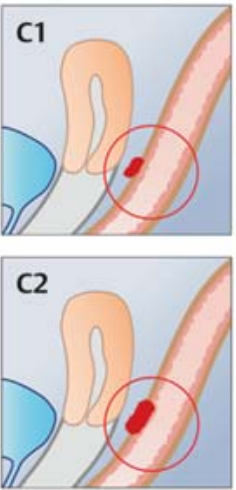

C3

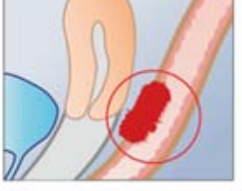

Fig. 1 ENZIAN classification of deep infiltrating endometriosis (www.endometriose-sef.de/dateien/ ENZIAN_2013_web.pdf; (c) Keckstein).

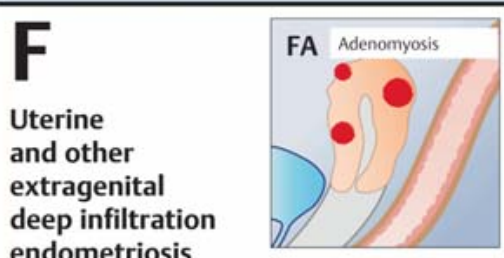

endometriosis
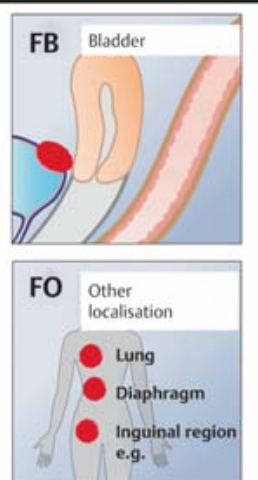

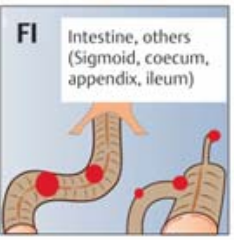

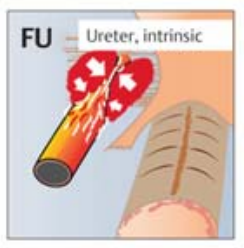

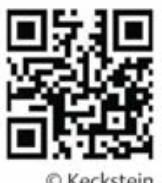

suppression of ovarian function. The drugs predominately used today are pure gestagens, gestagen-rich contraceptives, GnRH analogues and danazol. GnRH analogues are in such cases more effective than oral contraceptives or gestagens. A reduction of endometriosis-associated complaints can be achieved with all the mentioned substance classes, while GnRH analogues proved to be more effective for dysmenorrhoea and dyspareunia in some trials.

Some of these drugs are associated with appreciable and, above all, different side effects. GnRHa should only be administered together with the corresponding protective accompanying dugs ("add-back") because of the consequences of a possible oestrogen deficiency [1].

With regard to the response to hormone therapy it seems that peritoneal endometriosis differs from ovarian and deep infiltrating endometriosis. Duration of therapy with GnRH analogues amounts to 3-6 months. Although a 3-month therapy is equally effective the subsequent recurrence-free interval is then shorter [46]. Recent data from prospective studies have shown that dienogest as maintenance therapy after administration of GnRH can uphold the GnRH-induced effect for at least 12 months [47]. In 2 further RCCCTs equieffective actions of dienogest vs. GnRH analogues for endometriosis-associated pain were observed whereby with regard to clinical tolerance dienogest was better tolerated by the patients $[48,49]$. Although frequently used in clinical routine there is no evidence for a positive effect of NSAR on endometriosis-specific complaints [50].

\section{Ovarian endometriosis \\ Diagnostics}

The ovaries are attacked in up to $50 \%$ of all endometriosis patients $[1,51]$. Preoperative clarification is based on the clinical ex- 


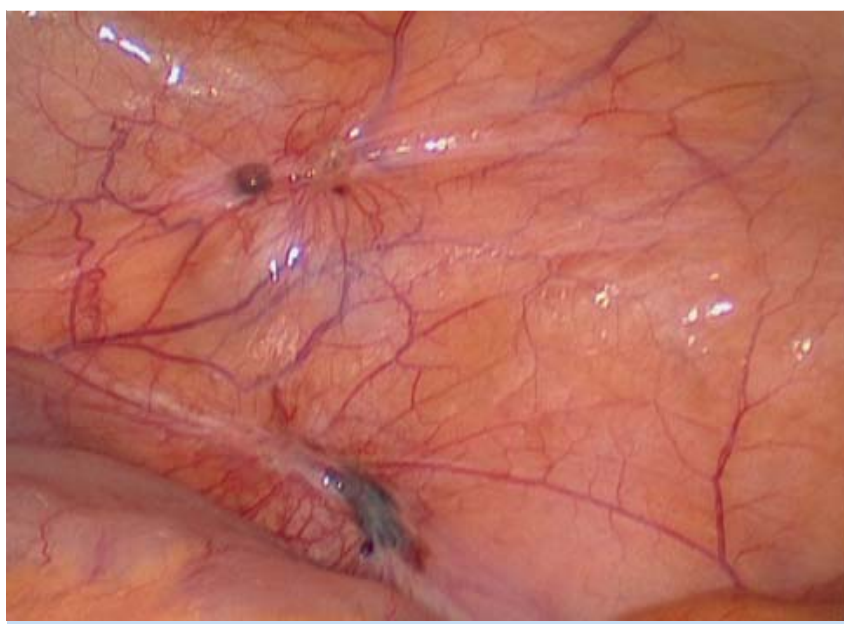

Fig. 2 Endometriosis attack of the peritoneum. Besides pigmented (= atypical) endometriosis lesions also typical, here, e.g., blister like unpigmented lesions can be seen.

amination. In the case of an ovarian endometrioma transvaginal sonography is suitable [51]. In cases of unclear ovarian space-filling lesions histological clarification is always required. The differential diagnosis, however, should take all ovarian findings into consideration and the results included in the operative procedures (especially LSC).

\section{Therapy}

The standard procedure is the laparoscopic removal of ovarian endometrioma [1]. In such cases the ovary-sparing extraction of the cyst bag is superior to thermal destruction [52]. Mere opening and lavage of the cyst bag as sole surgical intervention is not recommended due to the high rate of recurrences [53]. The recurrence rate even after 2 operative interventions can still amount to $20.8 \%$ and correlates above all with the duration of follow-up as well as the rASRM stage [54].

The exclusive use of drug therapy for ovarian endometrioma is not adequate and is not recommended [1]. Also postoperative $\mathrm{GnRH}$ analogues cannot compensate for an incomplete operation [55]. With regard to the recurrence rate data on the postoperative administration of a hormonal contraceptive are contradictory.

\section{Adenomyosis uteri \\ Diagnostics}

In the diagnostic work-up besides gynaecological examinations the transvaginal sonography (TVS) above all and if necessary MRI are most suitable in such cases. TVS is of greater relevance in daily practice [56]. The sonographic criteria for making a diagnosis are poorly delineated heterogeneous areas, in part, cystic intramural alterations, areas of changing echogenicity, irregular halo effects as well as a discrepancy between the anterior and posterior wall findings. Histological confirmation of adenomyosis is in most cases, however, only possible on hysterectomy samples.

\section{Therapy}

Therapy is adapted to the patient's family planning wishes. When family planning has been completed hysterectomy (HE) represents the most effective option. Here all common modalities of HE can be applied, but it must be taken into account that a possi- bly coexisting intraperitoneal endometriosis can usually not be managed by a purely vaginal procedure. A supracervical HE may also be envisioned but should not be performed in case of a concurrent coexisting rectovaginal endometriosis. When planning an $\mathrm{HE}$ the operative procedure should be decided upon between surgeon and patient on a case by case basis [1].

For patients still desiring to have children or with a wish to retain their organs, the benefit of an operation has not been demonstrated. Interventional radiological procedures (e.g., embolisation) or MRI-guided focussed ultrasound ablation are still in the experimental stage and should only be applied with the framework of clinical trials [1].

As alternatives to $\mathrm{HE}$, gestagens, hormonal contraceptives and intrauterine, local gestagen-releasing systems may be considered. The therapeutic effect is based on the induction of amenorrhoea. Contraceptives (monophasic formulations) and gestagens should therefore be taken continuously [1].

\section{Deeply Infiltrating Endometriosis}

In comparison to peritoneal or ovarian endometriosis, still very little is known about deeply infiltrating endometriosis (DIE) although it is a clinically no lesser relevant form of the disease. In this form it is seen that endometriosis - similar to malignant diseases - can spread beyond organ borders and infiltrate various structures. The thus resulting space-filling lesions and in part invasive growth can lead to indurations and finally to the destruction of functional mobile layers (e.g., between rectum and vagina) through to the occurrence of larger conglomerate tumours and in some cases even to disabling complaints.

The fact that, in Germany, statistically an interval of 6 years must pass from the first manifestation of symptoms to the diagnosis of endometriosis is disturbing and may in part be due to frequent misinterpretations and a lack of experience with the deeply infiltrating variant of the disease (see $\bullet$ Figs. 3 and 4) [1].

The mostly retroperitoneal growth of DIE is often not directly visible with laparoscopy - due either to the retroperitoneal position or complete Douglas obliteration - and thus it can hardly be defined in the common stage classifications (AFS/rASRM) [57]. DIE should thus additionally be described using the ENZIAN classification (see $\bigcirc$ Figs. 4 and 5) [40].

Frequently affected are the sacrouterine ligament, the parametria, the rectovaginal septum/fornix of the vagina, the rectosigmoid, the appendix, the urinary bladder and sometimes the ureter or also the small intestine.

\section{Symptoms}

The symptoms of DIE depend on the afflicted organs or, respectively, structures and vary between no complaints and disability and invalidisation due to severe pain. On the whole and as for endometriosis in general, there is no correlation between the extent of the disease and the severity of the symptom spectrum. A small node in the rectovaginal septum can, for example, make intercourse so painful that it is no longer possible and turn defaecation into a nightmare for the patients, whereas some other patients with stenosed rectum and/or space filling tumours through to frozen pelvis experience no complaints at all. In general, the symptoms of DIE, beside the classical dysmenorrhoea, do of course depend on the pattern of attack. Infiltration of the rectovaginal septum/fornix of the vagina or, respectively, the rectum often leads to dyspareunia and dyschezia, sometimes 


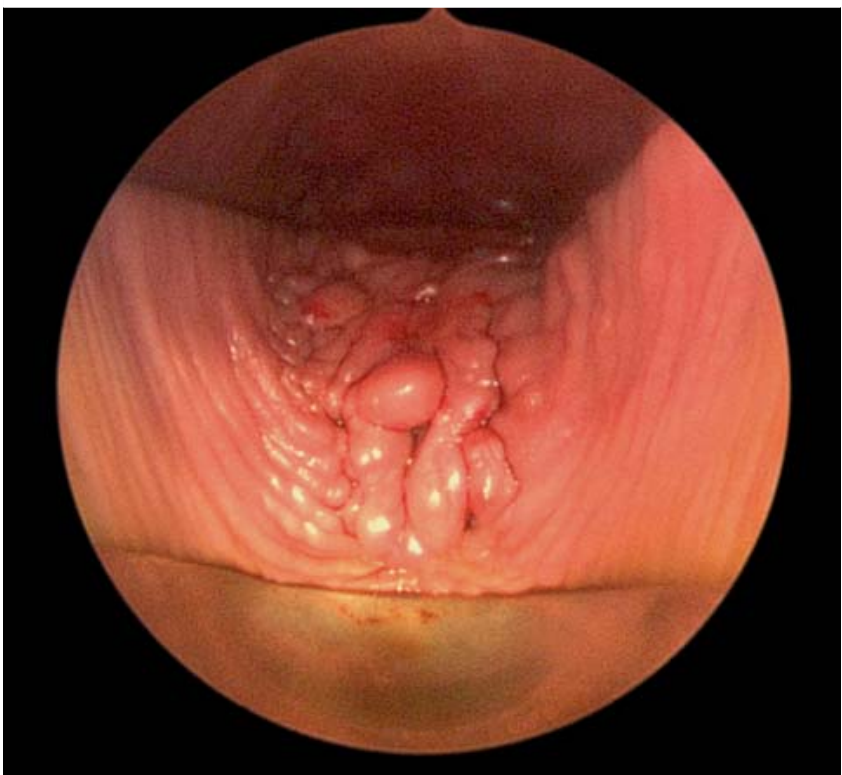

Fig. 3 Part of a DIE of the rectovaginal septum visible in the posterior fornix of the vagina.

also to flatulence and tenesmus and can be accompanied by rectal passage of mucous or blood as well as changes in stool behaviour through to paradox diarrhoea. DIE of the bladder or ureter can - beside hydronephrosis - cause dys- and haematuria. The lack of symptoms never excludes attack of the mentioned organs.

\section{Diagnostics}

The suspicion of DIE is based first of all on case history plus the clinical-gynaecological examination, where importance must be placed of an adequate deconvulation of the posterior fornix of the vagina in the speculum settings (see $\bullet$ Fig. 3) and a rectal or rectovaginal palpation. Typically among the findings to be recorded - apart from pain trigger points - are visible endometriosis in the vagina, the rough nodular induration of the rectovaginal septum

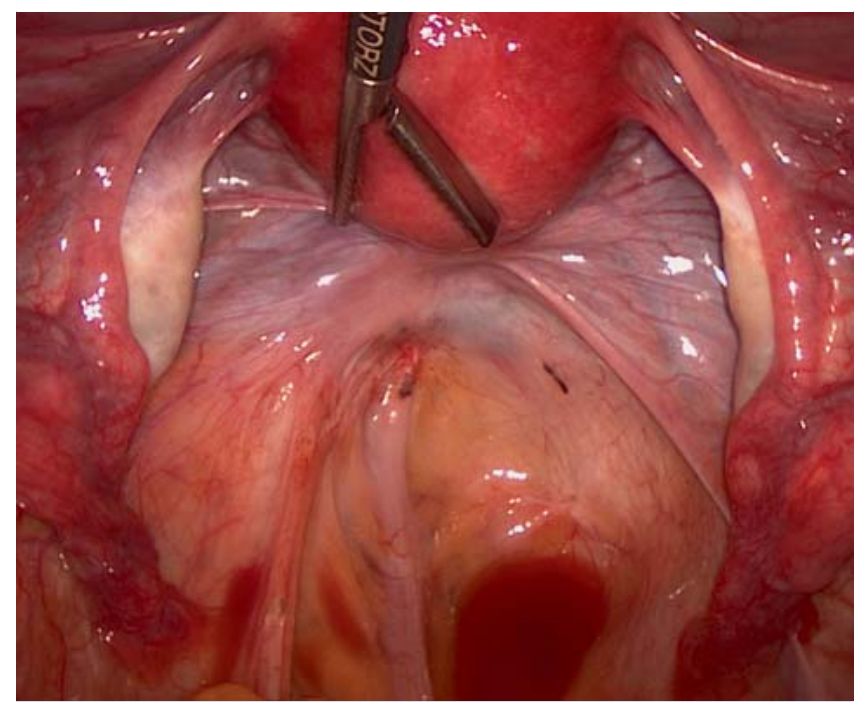

Fig. 4 Due to the almost exclusive retroperitoneal position the DIE of the rectovaginal septum and the rectum ( $\mathrm{AASRM} \mathrm{I})$ is easily missed, see - Fig. 5. or the parametria/sacrouterine ligaments and, in some cases, urinary retention on sonography. With sufficient experience an infiltration of the rectovaginal septum and the rectum can also be demonstrated by transvaginal sonography $[51,56]$. The sonographic detection of bilateral endometrioma (especially in the sense of kissing ovaries) can be suggestive of DIE [58].

In the literature magnetic resonance imaging exhibits a high sensitivity for the diagnosis of FDI but is certainly dependent on the investigator's experience or, respectively, knowledge of the disease but only rarely does it lead to a change of the therapy [59, $60]$. In cases of suspected intestinal involvement by DIE coloscopy is rarely useful since the endometrial infiltration usually stops at the mucosa so that the exclusion of intestinal attack is not possible by rectoscopy. In such cases rectal endosonography is to be preferred $[1,59]$. Coloscopy must only be used when it is necessary to exclude other differential diagnoses (e.g. colon cancer, diverticulitis, chronic inflammatory bowel disease). DIE of the bladder can often be well visualised by sonography when the bladder is sufficiently full. In such cases, however, cystoscopy prior to surgery is reasonable in order to estimate the distance to the trigonum vesicae and the ureter orifices and, if necessary, to carry out thereby a splinting with a double J catheter.

\section{Therapy}

The therapy of choice for symptomatic DIE is resection with healthy margins [61-64]. The operations often include rectum resection (mostly en-bloc with the afflicted rectovaginal septum and the vagina), and partial resection of the sacrouterine ligament and parametria as well as parts of the bladder (see $\bullet$ Figs. 4 to 7). Partial ureter resections with new implantation (e.g., psoashitch plasty) are much more rarely needed. Hysterectomy is not obligatory and is not wanted by the mostly young patients. The interventions can mostly be performed as laparoscopic or, if necessary vaginal-assisted procedures. Good cooperation between the various disciplines (gynaecology, surgery, urology) is a necessity and accordingly is required for the certification of specialised surgical centres by the Stiftung Endometrioseforschung, the Europäische Endometrioseliga and the Endometriose-Vereinigung-Deutschland e.V.

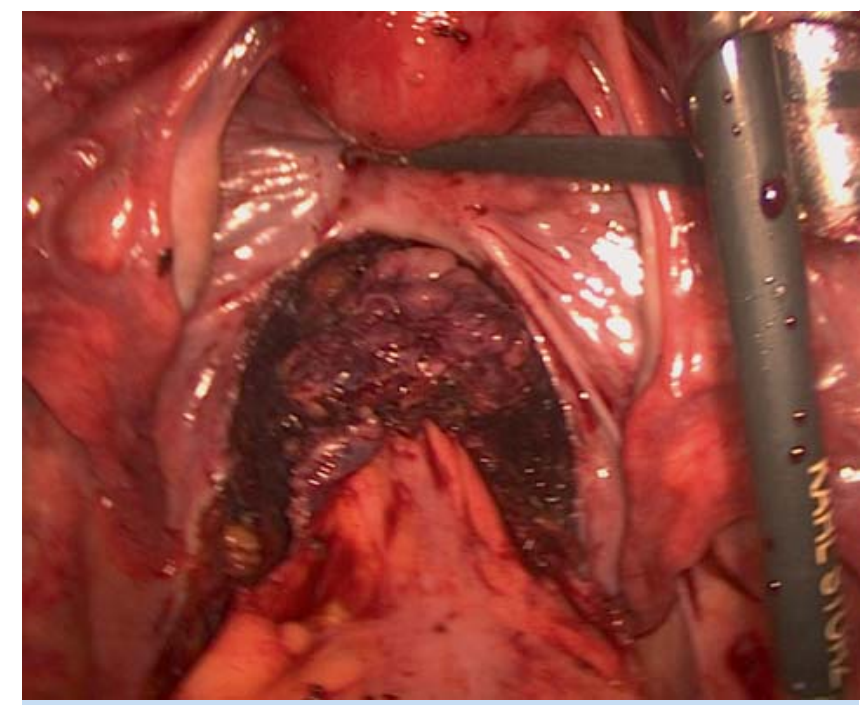

Fig. 5 View from $\bullet$ Fig. 4 with freely exposed retroperitoneal endometriosis lesion (ENZIAN 2A, 2C). 


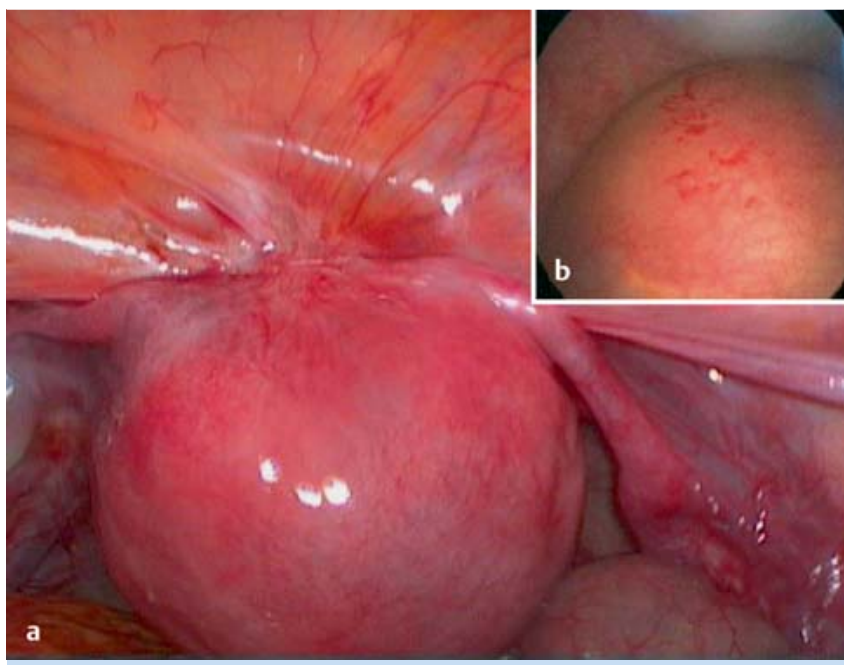

Fig. $\mathbf{6} \mathbf{a}$ and $\mathbf{b}$ a DIE of the vesicocervical septum and bladder. b Cystoscopic visualisation with intact urothelium over the finding.

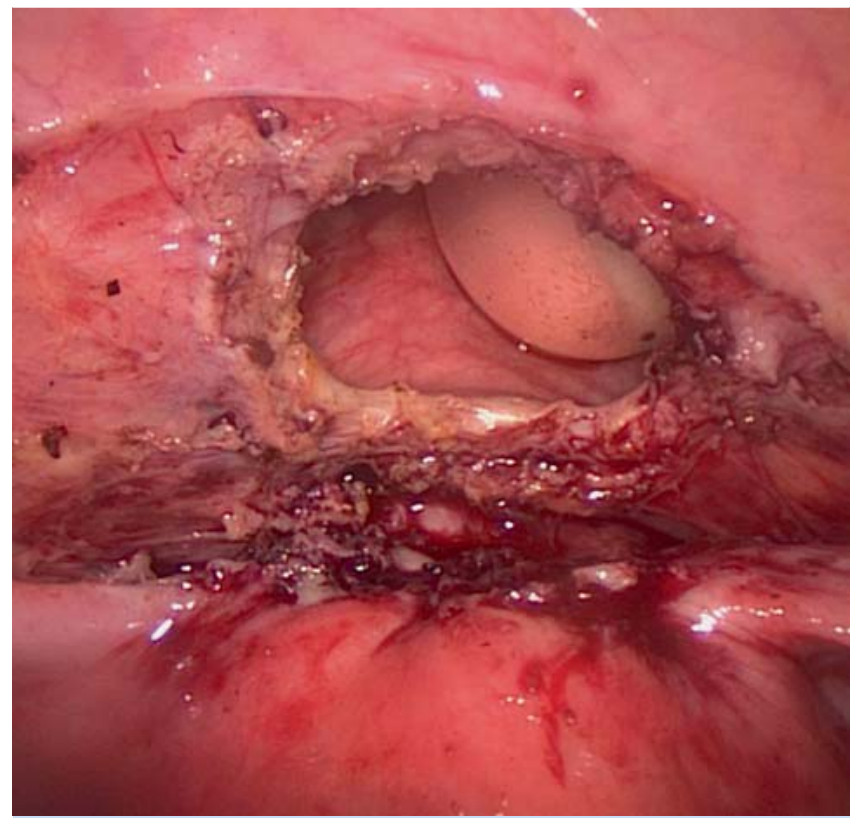

Fig. 7 Situation after local full wall excision of DIE of the bladder.
Urinary retention - due to extrinsic or intrinsic DIE of the ureter is the only acceptable absolute indication for surgery in the German-language guidelines since it is essential to prevent persisting damage to the kidneys [1]. An intestinal perforation or ileus due to stenosing DIE of the bowels can give rise to an urgent indication in a similar manner [65].

In the case of DIE diagnosed near to the ureter or its recent operative management long-term biannual sonography of the kidneys is recommended in order to recognise the potentially slowly but then also often asymptomatical development of urinary retention in a timely manner [1].

The decision for or against operative removal of DIE is - when as in most cases no absolute indication is given - made together with the patient on the basis of the symptoms and the level of suffering. In most cases an estimation of the extent by means of an at first purely diagnostic laparoscopy is helpful for both physician and patient. In no case may the decision be made without sufficient counselling and time for consideration since extensive rehabilitating resection with participation of the bowels and/or bladder interventions do not guarantee either therapeutic success or freedom from de novo complaints resulting from surgery (late postoperative problems due to disorders of defaecation or to scar and adhesion complaints) [62,66]. An appropriately high burden of suffering is a decisive prerequisite for rehabilitating operations.

Critical in this context is always the wish for removal of an asymptomatic DIE merely on the basis of sterility. In the literature higher rates of not only spontaneous but also of IVF-induced pregnancies after complete resections in such cases can be found in the literature [67-69], however, the potential operative morbidity that is to be expected must be also be considered. In the worst case a previously complaint-free but infertile patient - in spite of unsuccessful IVF - may merely experience a marked deterioration in her quality of life. Such scenarios must also be discussed in detail with just those patients who are free of symptoms. More recent data also even additionally question this im- provement in fertility, so that the guideline recommendations will probably have to be reassessed on this point [70].

Drug therapy is neither necessary as preparation nor as an adjuvant therapy after the surgical management of DIE. When, in spite of symptomatic DIE - initial or permanent - the decision against surgery is made, the classical hormone therapy options (monophasic oral contraceptives, gestagen monotherapy, levonorgestrel IUP) can then be applied. An effect can only be expected during the therapy so that a life-long continuation is a necessity [1].

A malignant degeneration is rare but possible. DIE can typically develop into endometrioid or clear-cell adenocarcinomas in the pelvis without any clearly associated organs [71]. However, this risk is so low that an indication for treatment or surgery cannot be derived from this alone.

\section{Endometriosis and Sterility \\ $\nabla$}

\section{Pathophysiology of involuntary childlessness}

in cases of endometriosis

There is a high coincidence between sterility and endometriosis [72], the reasons for this have not yet been clarified. It is estimated that $30-50 \%$ of the women with endometriosis are infertile [73]. Mechanical factors due to adhesions of the adnexa with disorders of tube motility or, respectively, the ovum pick-up mechanism have been accepted as reasons for sterility. Further causes may involve disordered immunological dysregulation and also a change of the intra-abdominal milieu, due to cytokines, prostaglandins and macrophages. In an egg cell donation programme patients with endometriosis achieved similar pregnancy rates as those women without endometriosis, however the pregnancy rates in case of transfer of embryos form women with endometriosis was markedly lower. This suggests a decrease in embryo quality in cases of endometriosis [74]. 


\section{Drug therapy}

A hormone therapy for endometriosis can be performed with pure gestagens (e.g., dienogest, medroxyprogesterone acetate, levonorgestrel, chlormadinone acetate, cyproterone acetate and nomegestrol acetate), with monophasic oestrogen-gestagen combination formulations (especially taken in long cycles), as well as by means of GnRH analogues. In cases of low-degree endometriosis (AFS I and II), however, a metaanalysis of 16 randomised and controlled studies did not reveal an improvement in fertility after drug treatment (GnRH analogues, gestagens) in comparison to placebo or expectative procedure [75]. A postoperative drug therapy with GnRH agonists could not improve the spontaneous pregnancy rates of sterility patients and is thus not recommended [55].

\section{Operative therapy}

Just for patients desiring to have children and the suspicion of an endometrial disease surgical diagnosis and histological confirmation with simultaneous hysterectomy and chromopertubation of the Fallopian tubes represent the method of choice. In the course of this treatment if at all possible all endometriosis lesions should be surgically excised or thermally destroyed. Endometriosis cysts should be ablated with cyst bag in an organ-sparing manner. The rate of spontaneous pregnancies is in such cases also higher than for the excision endometriosis lesions in stages AFS I and II [52, $53,76]$.

\section{Assisted reproduction}

The measures of assisted reproduction in almost all stages of endometriosis seem to be more advantageous as compared with a non-surgical process. In cases of minimal endometriosis the probability of a pregnancy after a wait-and-see procedure for 6 months amounts to $28 \%$ [77].

Several prospective controlled studies have shown a higher success rate under ovarian stimulation in combination with intrauterine insemination [77]. For younger patients pregnancies occurred within the first cycle after operative management of endometriosis so that a maximum of 3 insemination treatments should be performed [78].

For endometriosis patients the success rate in the course of an invitro fertilisation is up to $50 \%$ lower than for tubular sterility [79], furthermore, higher drug doses are needed for the markedly lower responsiveness to gonadotropins [80]. On the basis of a large metaanalysis it has been shown that the implantation rate for endometriosis patients was markedly lower than that in the control group (12.72 vs. $18.08 \%$ ) [79]. In case of the recurrence of an extensive endometriosis an assisted reproduction by means of invitro fertilisation is superior to renewed operative therapy with regard to the pregnancy rate [81]. In the case of advanced endometriosis AFS III and IV, a stimulation for IVF/ICSI in ultra-long protocol after surgical therapy for endometriosis leads to significantly higher pregnancy rates $[82,83]$.

In patients with endometriosis and the desire to have children surgical clarification and rehabilitation of endometriosis is considered to be the gold standard. Depending on the degree of severity of the endometriosis, a cycle optimisation in combination with ovarian stimulation and accompanying intrauterine insemination should be preferred although not more than 3 treatment cycles may be carried out.

Patients with severe endometriosis should be treated as early as possible by means of IVF/ICSI, if necessary after stimulation in ultra-long protocol.

\section{Complementary Therapy, Rehabilitation and Follow-Up $\nabla$}

For chronic courses of endometriosis with the corresponding symptoms many women experience an alleviation of their complaints and an improvement in their quality of life through the use of complementary therapies such as, e.g., acupuncture, Chinese medicine, homeopathy, phytotherapy, osteopathy, physiotherapy etc. However, at present there are no randomised and controlled studies that confirm an evidence-based effect of these therapies [1].

The need for rehabilitation is often present after extensive surgical interventions or in patients with chronic pain. The aim of rehabilitation should be the restoration of physical, mental and social well-being and should thus be generously offered to this patient collective. An important aspect is, however, also the confrontation with the disease, which often has a chronic course and in part is accompanied by unavoidable restrictions and complaints. Afflicted women should be referred to regional and national self-help organisations and self-help groups. The aftercare should be oriented on the symptoms. The patient's quality of life is in the forefront of all efforts [1].

In the present article we have topically summarised many aspects of endometriosis with reference to the most recent literature. In particular the less common DIE, a form that is associated with a high morbidity, has been discussed in detail. Also sterility as well as the diagnostic and therapeutic consequences are specifically summarised. Besides further important clinical aspects we have in the present article highlighted the most recent research results, in order to close the gap concerning actual research between scientists and clinicians.

\section{Conflict of Interest}

None.

\section{References}

1 Ulrich U, Buchweitz O, Greb R et al. Interdisciplinary S2k guidelines for the diagnosis and treatment of endometriosis: short version - AWMF Registry No.015-045, August 2013. Geburtsh Frauenheilk 2013; 73: 890-898

2 Burghaus S, Klingsiek P, Fasching PA et al. Risk factors for endometriosis in a German case-control study. Geburtsh Frauenheilk 2011; 71: 1073-1079

3 Siedentopf F. Chronic pain syndromes in gynaecological practice: endometriosis and fibromyalgia. Geburtsh Frauenheilk 2012; 72: 10921098

4 Wölfler MM, Stadermann M, Rath W et al. Anamnestisches Screening bei symptomatischen Patientinnen mit und ohne Endometriose. Geburtsh Frauenheilk 2011; 71: 53-58

5 Oppelt P, Chavtal R, Haas D et al. Costs of in-patient treatment for endometriosis in Germany 2006: an analysis based on the G-DRG-Coding. Gynecol Endocrinol 2012; 28: 903-905

6 Hudelist G, Fritzer N, Thomas A et al. Diagnostic delay for endometriosis in Austria and Germany: causes and possible consequences. Hum Reprod 2012; 27: 3412-3416

7 Sasson IE, Taylor HS. Stem cells and the pathogenesis of endometriosis. Ann N Y Acad Sci 2008; 1127: 106-115

8 Sampson JA. Peritoneal endometriosis due to menstrual dissemination of endometrial tissues into the peritoneal cavity. Am J Obstet Gynecol 1927; 14: 422-469

9 Halme J, Hammond MG, Hulka JF et al. Retrograde menstruation in healthy women and in patients with endometriosis. Obstet Gynecol 1984; 64: 151-154 
10 Augoulea A, Alexandrou A, Creatsa M et al. Pathogenesis of endometriosis: the role of genetics, inflammation and oxidative stress. Arch Gynecol Obstet 2012; 286: 99-103

11 Rahmioglu N, Missmer SA, Montgomery GW et al. Insights into assessing the genetics of endometriosis. Curr Obstet Gynecol Rep 2012; 1: 124137

12 Rier SE. The potential role of exposure to environmental toxicants in the pathophysiology of endometriosis. Ann N Y Acad Sci 2002; 955: 201-212; discussion 230-232, 396-406

13 Bellelis P, Podgaec S, Abrao MS. Environmental factors and endometriosis. Rev Assoc Med Bras 2011; 57: 448-452

14 Barrier BF. Immunology of endometriosis. Clin Obstet Gynecol 2010; 53: $397-402$

15 Mathur SP. Autoimmunity in endometriosis: relevance to infertility. Am J Reprod Immunol 2000; 44: 89-95

16 de Ziegler D, Borghese B, Chapron C. Endometriosis and infertility: pathophysiology and management. Lancet 2010; 376: 730-738

17 Slabe N, Meden-Vrtovec H, Verdenik I et al. Cytotoxic T-cells in peripheral blood in women with endometriosis. Geburtsh Frauenheilk 2013; 73: $1042-1048$

18 May KE, Conduit-Hulbert SA, Villar J et al. Peripheral biomarkers of endometriosis: a systematic review. Hum Reprod Update 2010; 16: 651674

19 Khoufache K, Michaud N, Harir N et al. Anomalies in the inflammatory response in endometriosis and possible consequences: a review. Minerva Endocrinol 2012; 37: 75-92

20 Alpay Z, Saed GM, Diamond MP. Female infertility and free radicals: potential role in adhesions and endometriosis. J Soc Gynecol Investig 2006; 13: 390-398

21 Gargett CE, Masuda H. Adult stem cells in the endometrium. Mol Hum Reprod 2010; 16: 818-834

22 Figueira PG, Abrao MS, Krikun G et al. Stem cells in endometrium and their role in the pathogenesis of endometriosis. Ann N Y Acad Sci 2011; 1221: 10-17

$23 \mathrm{Du}$ H, Taylor HS. Stem cells and reproduction. Curr Opin Obstet Gynecol 2010; 22: 235-241

24 Laschke MW, Giebels C, Menger MD. Vasculogenesis: a new piece of the endometriosis puzzle. Hum Reprod Update 2011; 17: 628-636

25 Groothuis PG, Nap AW, Winterhager E et al. Vascular development in endometriosis. Angiogenesis 2005; 8: 147-156

26 Nisolle M, Casanas-Roux F, Anaf Vet al. Morphometric study of the stromal vascularization in peritoneal endometriosis. Fertil Steril 1993; 59: 681-684

27 McLaren J. Vascular endothelial growth factor and endometriotic angiogenesis. Hum Reprod Update 2000; 6: 45-55

28 Laschke MW, Menger MD. In vitro and in vivo approaches to study angiogenesis in the pathophysiology and therapy of endometriosis. Hum Reprod Update 2007; 13: 331-342

29 Healy DL, Rogers PA, Hii L et al. Angiogenesis: a new theory for endometriosis. Hum Reprod Update 1998; 4: 736-740

30 Laschke MW, Elitzsch A, Vollmar B et al. Combined inhibition of vascular endothelial growth factor (VEGF), fibroblast growth factor and platelet-derived growth factor, but not inhibition of VEGF alone, effectively suppresses angiogenesis and vessel maturation in endometriotic lesions. Hum Reprod 2006; 21: 262-268

31 Feng $D$, Welker $S$, Korbel C et al. Protein kinase CK2 is a regulator of angiogenesis in endometriotic lesions. Angiogenesis 2012; 15: 243-252

32 Laschke MW, Menger MD. Anti-angiogenic treatment strategies for the therapy of endometriosis. Hum Reprod Update 2012; 18: 682-702

33 Anaf V, Simon P, El Nakadi I et al. Hyperalgesia, nerve infiltration and nerve growth factor expression in deep adenomyotic nodules, peritoneal and ovarian endometriosis. Hum Reprod 2002; 17: 1895-1900

34 Alvarez P, Chen X, Hendrich J et al. Ectopic uterine tissue as a chronic pain generator. Neuroscience 2012; 225: 269-282

35 Asante A, Taylor RN. Endometriosis: the role of neuroangiogenesis. Annu Rev Physiol 2011; 73: 163-182

36 Novella-Maestre E, Herraiz S, Vila-Vives JM et al. Effect of antiangiogenic treatment on peritoneal endometriosis-associated nerve fibers. Fertil Steril 2012; 98: 1209-1217

37 Rimbach S, Ulrich U, Schweppe KW. Surgical therapy of endometriosis: challenges and controversies. Geburtsh Frauenheilk 2013; 73: 918923

38 Revised American Society for Reproductive Medicine classification of endometriosis: 1996. Fertil Steril 1997; 67: 817-821
39 Haas D, Wurm P, Shamiyeh A et al. Efficacy of the revised Enzian classification: a retrospective analysis. Does the revised Enzian classification solve the problem of duplicate classification in rASRM and Enzian? Arch Gynecol Obstet 2013; 287: 941-945

40 Tuttlies $F$, Keckstein J, Ulrich $U$ et al. [ENZIAN-score, a classification of deep infiltrating endometriosis]. Zentralbl Gynakol 2005; 127: 275281

41 Jansen RP, Russell P. Nonpigmented endometriosis: clinical, laparoscopic, and pathological definition. Am J Obstet Gynecol 1986; 155: 11541159

42 Harrison RF, Barry-Kinsella C. Efficacy of medroxyprogesterone treatment in infertile women with endometriosis: a prospective, randomized, placebo-controlled study. Fertil Steril 2000; 74: 24-30

43 Renner SP, Rix S, Boosz A et al. Preoperative pain and recurrence risk in patients with peritoneal endometriosis. Gynecol Endocrinol 2010; 26: 230-235

44 Healey M, Ang WC, Cheng C. Surgical treatment of endometriosis: a prospective randomized double-blinded trial comparing excision and ablation. Fertil Steril 2010; 94: 2536-2540

45 Duffy JM, Arambage K, Correa FJ et al. Laparoscopic surgery for endometriosis. Cochrane Database Syst Rev 2014; 4: CD011031

46 Hornstein MD, Yuzpe AA, Burry KA et al. Prospective randomized double-blind trial of 3 versus 6 months of nafarelin therapy for endometriosis associated pelvic pain. Fertil Steril 1995; 63: 955-962

47 Kitawaki J, Kusuki I, Yamanaka K et al. Maintenance therapy with dienogest following gonadotropin-releasing hormone agonist treatment for endometriosis-associated pelvic pain. Eur J Obstet Gynecol Reprod Biol 2011; 157: 212-216

48 Strowitzki T, Marr J, Gerlinger C et al. Detailed analysis of a randomized, multicenter, comparative trial of dienogest versus leuprolide acetate in endometriosis. Int J Gynaecol Obstet 2012; 117: 228-233

49 Harada T, Momoeda M, Taketani Y et al. Dienogest is as effective as intranasal buserelin acetate for the relief of pain symptoms associated with endometriosis-a randomized, double-blind, multicenter, controlled trial. Fertil Steril 2009; 91: 675-681

50 Allen C, Hopewell S, Prentice A et al. Nonsteroidal anti-inflammatory drugs for pain in women with endometriosis. Cochrane Database Syst Rev 2009; 2: CD004753

51 Hudelist G, Oberwinkler KH, Singer CF et al. Combination of transvaginal sonography and clinical examination for preoperative diagnosis of pelvic endometriosis. Hum Reprod 2009; 24: 1018-1024

52 Hart RJ, Hickey M, Maouris $P$ et al. Excisional surgery versus ablative surgery for ovarian endometriomata. Cochrane Database Syst Rev 2008; 2: CD004992

53 Alborzi S, Momtahan M, Parsanezhad ME et al. A prospective, randomized study comparing laparoscopic ovarian cystectomy versus fenestration and coagulation in patients with endometriomas. Fertil Steril 2004; 82: 1633-1637

54 Kim ML, Kim JM, Seong SJ et al. Recurrence of ovarian endometrioma after second-line, conservative, laparoscopic cyst enucleation. Am J Obstet Gynecol 2014; 210: 216 e1-216 e6

55 Busacca M, Somigliana E, Bianchi S et al. Post-operative GnRH analogue treatment after conservative surgery for symptomatic endometriosis stage III-IV: a randomized controlled trial. Hum Reprod 2001; 16: 2399-2402

56 Hudelist G, Keckstein J. [The use of transvaginal sonography (TVS) for preoperative diagnosis of pelvic endometriosis]. Praxis (Bern 1994) 2009; 98: 603-607

57 Khong SY, Bignardi T, Luscombe G et al. Is pouch of Douglas obliteration a marker of bowel endometriosis? J Minim Invasive Gynecol 2011; 18: 333-337

58 Redwine $D B$. Ovarian endometriosis: a marker for more extensive pelvic and intestinal disease. Fertil Steril 1999; 72: 310-315

59 Bazot $M$, Lafont $C$, Rouzier $R$ et al. Diagnostic accuracy of physical examination, transvaginal sonography, rectal endoscopic sonography, and magnetic resonance imaging to diagnose deep infiltrating endometriosis. Fertil Steril 2009; 92: 1825-1833

60 Saba L, Guerriero S, Sulis R et al. Learning curve in the detection of ovarian and deep endometriosis by using magnetic resonance: comparison with surgical results. Eur J Radiol 2011; 79: 237-244

61 Chopin N, Vieira M, Borghese B et al. Operative management of deeply infiltrating endometriosis: results on pelvic pain symptoms according to a surgical classification. J Minim Invasive Gynecol 2005; 12: 106112 
62 Minelli L, Fanfani F, Fagotti A et al. Laparoscopic colorectal resection for bowel endometriosis: feasibility, complications, and clinical outcome. Arch Surg 2009; 144: 234-239; discussion 239

63 Haggag H, Solomayer E, Juhasz-Boss I. The treatment of rectal endometriosis and the role of laparoscopic surgery. Curr Opin Obstet Gynecol 2011; 23: 278-282

64 Juhasz-Boss I, Lattrich C, Furst A et al. Severe endometriosis: laparoscopic rectum resection. Arch Gynecol Obstet 2010; 281: 657-662

65 Decker D, Konig J, Wardelmann E et al. Terminal ileitis with sealed perforation-a rare complication of intestinal endometriosis: case report and short review of the literature. Arch Gynecol Obstet 2004; 269: 294-298

66 Possover M. Laparoscopic management of neural pelvic pain in women secondary to pelvic surgery. Fertil Steril 2009; 91: 2720-2725

67 Bianchi PH, Pereira RM, Zanatta A et al. Extensive excision of deep infiltrative endometriosis before in vitro fertilization significantly improves pregnancy rates. J Minim Invasive Gynecol 2009; 16: 174-180

68 Chapron C, Fritel X, Dubuisson JB. Fertility after laparoscopic management of deep endometriosis infiltrating the uterosacral ligaments. Hum Reprod 1999; 14: 329-332

69 Littman E, Giudice L, Lathi R et al. Role of laparoscopic treatment of endometriosis in patients with failed in vitro fertilization cycles. Fertil Steril 2005; 84: 1574-1578

70 Douay-Hauser N, Yazbeck C, Walker F et al. Infertile women with deep and intraperitoneal endometriosis: comparison of fertility outcome according to the extent of surgery. J Minim Invasive Gynecol 2011; 18: 622-628

71 Ulrich $U$, Rhiem $K$, Kaminski $M$ et al. Parametrial and rectovaginal adenocarcinoma arising from endometriosis. Int J Gynecol Cancer 2005; 15: 1206-1209

72 Pritts EA, Taylor RN. An evidence-based evaluation of endometriosisassociated infertility. Endocrinol Metab Clin North Am 2003; 32: 653667
73 Practice Committee of the American Society for Reproductive Medicine. Endometriosis and infertility. Fertil Steril 2006; 86 (5 Suppl. 1): S156S160

74 Simon C, Gutierrez A, Vidal A et al. Outcome of patients with endometriosis in assisted reproduction: results from in-vitro fertilization and oocyte donation. Hum Reprod 1994; 9: 725-729

75 Hughes E, Brown J, Collins JJ et al. Ovulation suppression for endometriosis. Cochrane Database Syst Rev 2007; 3: CD000155

76 Jacobson TZ, Duffy JM, Barlow D et al. Laparoscopic surgery for subfertility associated with endometriosis. Cochrane Database Syst Rev 2010; 1: CD001398

77 Tummon IS, Asher LJ, Martin JS et al. Randomized controlled trial of superovulation and insemination for infertility associated with minimal or mild endometriosis. Fertil Steril 1997; 68: 8-12

78 Greb R. Ovarielle Stimulation und intrauterine Insemination: Sinnvolle Therapie bei endometrioseassoziierter Sterilität? Gynak Endokrinol 2004; 2: 194-200

79 Barnhart K, Dunsmoor-Su R, Coutifaris C. Effect of endometriosis on in vitro fertilization. Fertil Steril 2002; 77: 1148-1155

80 Mahutte NG, Arici A. Endometriosis and assisted reproductive technologies: are outcomes affected? Curr Opin Obstet Gynecol 2001; 13: 275-279

81 Pagidas $K$, Falcone T, Hemmings $R$ et al. Comparison of reoperation for moderate (stage III) and severe (stage IV) endometriosis-related infertility with in vitro fertilization-embryo transfer. Fertil Steril 1996; 65: 791-795

82 Rickes D, Nickel I, Kropf S et al. Increased pregnancy rates after ultralong postoperative therapy with gonadotropin-releasing hormone analogs in patients with endometriosis. Fertil Steril 2002; 78: 757-762

83 Sallam HN, Garcia-Velasco JA, Dias S et al. Long-term pituitary downregulation before in vitro fertilization (IVF) for women with endometriosis. Cochrane Database Syst Rev 2006; 1: CD004635 